\title{
TLC separation of hippuric, mandelic, and phenylglyoxylic acids from urine after mixed exposure to toluene and styrene
}

\author{
GRAŻYNA BIENIEK, EWA PAŁYS, AND T WILCZOK \\ From the Institute of Chemistry and Physics, Silesian Medical Academy, Sosnowiec, Poland
}

\begin{abstract}
A method using thin-layer chromatography is described to determine the concentration of hippuric acid, mandelic acid, and phenylglyoxylic acid present in the urine after occupational mixed exposure to toluene and styrene. These substances are known metabolites of toluene and styrene, and therefore the evaluation to mixed exposure to toluene and styrene may be carried out separating these metabolites beforehand. Procedures are proposed to separate the metabolites as follows: (1) separation of hippuric acid from mandelic acid, (2) separation of mandelic acid from phenylglyoxylic acid, and (3) separation of hippuric acid and mandelic acid from phenylglyoxylic acid. The developing reagent $\mathrm{p}$-dimethylaminobenzaldehyde in acetic acid anhydride was used after separation on Kieselgel and Silicagel. The sensitivity of the method was $6 \mu \mathrm{g}$ of hippuric acid, $10 \mu \mathrm{g}$ of mandelic acid, and $7 \mu \mathrm{g}$ of phenylglyoxylic acid with an average recovery of $94 \%$.
\end{abstract}

The evaluation of professional exposure to styrene is based on the determination of mandelic acid ${ }^{1-3}$ or mandelic and phenylglyoxylic acids 5 in the urine. Ikeda $e^{e} a l^{6}$ and Horigushi et al ${ }^{7}$ described the usefulness of hippuric, phenylglyoxylic, and mandelic acid determination in the urine after exposure to styrene. Hippuric acid is the main metabolite of styrene in animals ${ }^{3}$ and the main metabolite after exposure to toluene ${ }^{8}{ }^{9}$; hippuric acid is also found in the urine after exposure to benzylamines. ${ }^{10}$ Some separation procedures of mandelic and phenylglyoxylic acids have been described using gas chromatography11-13; a colorimetric method is described for determining these metabolites using TLC techniques, ${ }^{4}$ but at the same time hippuric acid was analysed separately, according to the method of Ikeda and Ohtsuji. ${ }^{14}$

The aim of the present work was to elaborate a simple method for the simultaneous quantitative determination of hippuric, mandelic, and phenylglyoxylic acids by using thin-layer chromatography. There are large discrepancies among various authors concerning the evaluation of metabolites in the urine after professional exposure to styrene, and therefore the present method enables the direct

Received 3 July 1981

Accepted 11 August 1981 use in following variations: two from the three analysed compounds or all three compounds.

\section{Material and methods}

The general separation procedure was carried out in aqueous solutions of the metabolite mixtures and proved in urine samples, to which given amounts of the analysed compounds were administered. The final results were checked in urine samples collected from individuals exposed to styrene.

For mandelic and phenylglyoxylic acid determination, urine samples were extracted by using ethyl ether. Because of rather low solubility of hippuric acid in ethyl ether,when all three compounds were analysed, chloroform was used for the extraction or urine samples were directly administered to the TLC plates. Such urine samples were evaporated under vacuum (10:1 (v:v) ) before use.

\section{ADSORBENTS USED}

Chromatographic plates covered with Silicagel LS $5 / 40 \mu$, Kieselgel $\mathrm{H}$, Kieselgel $\mathrm{HF}_{254}$, Kieselgel $\mathrm{H}$ type 60, MN Kieselgel G, and MN Kieselgel $\mathrm{H}$ were used. The layer thickness of the sorbent on plates dried at room temperature for $10-15 \mathrm{~min}$ was 0.25 $\mathrm{mm}$. The plates were activated for one hour, dried again at $105^{\circ} \mathrm{C}$, and stored in a desiccator over $\mathrm{CaCl}_{2}$. 
Among various developing systems and developing reagents used the following ones are proposed as being in good agreement with quantitative control experiments.

\section{DEVELOPING SYSTEMS}

\section{Metabolite mixtures}

I Hippuric acid (HA)-mandelic acid (MA).

II Mandelic acid (MA)-phenylglyoxylic acid (PGA). III Hippuric acid (HA)-mandelic acid (MA)-phenylglyoxylic acid (PGA).

DEVELOPING SYSTEMS IN $\mathrm{V} / \mathrm{V}$

(A) Light petroleum-n-butyl alcohol-chloroformacetic acid $(3: 3: 4: 2)$.

(B) Light petroleum-chloroform-acetic acid (3:4:2).

(C) n-butyl alcohol-formic acid-water $(3: 2: 1)$.

(D) Light petroleum-benzene-chloroform-acetic acid $(4: 1: 3: 2)$.

(E) n-butyl alcohol-formic acid-water (4:1:1).

(F) Chloroform-acetic acid-water $(4: 1: 1)$ chloroform layer used after having solvent mixture shaken and separated.

(G) n-butyl alcohol-chloroform-acetic acid-water $(5: 2: 1: 4)$.

(H) Light petroleum-benzene-chloroform-acetic acidwater $(3: 3: 4: 2: 2)$.

\section{DEVELOPING REAGENTS}

The following developing systems were used given that all are able to form coloured compounds with aromatic acids:

(a) p-dimethylaminobenzaldehyde $(4 \mathrm{~g}$ was dissolved in $100 \mathrm{ml}$ of acetic acid anhydride together with $1 \mathrm{~g}$ of sodium acetate),

(b) methyl red reagent, ethanol solution $0 \cdot 1 \%$, and

(c) o-bromophenol red ethanol solution $(0.04 \%)$,

(d) bromophenol blue ethanol solution $0.04 \%$, $\mathrm{pH}=6 \cdot 7$.

Spectrophotometric absorption measurements were carried out on the substances taken from plates after reaction with p-dimethylaminobenzaldehyde in acetic anhydride using a recording Carl Zeiss UVVis spectrophotometer.

Procedure-One $\mathrm{ml}$ of urine acidified with two drops of concentrated $\mathrm{H}_{2} \mathrm{SO}_{4}$ was twice extracted with $5 \mathrm{ml}$ of ethyl ether and strongly shaken. The extract was concentrated to a volume of $1 \mathrm{ml}$. When the person is also exposed to toluene it is suggested that chloroform be used for urine extraction; alternatively, the urine may be concentrated under low pressure to small volumes. Aliquots of $100 \mu \mathrm{l}$ were used for each analysis, and the chromatographic plates were developed in one of the solutions described above, depending on the aim of the procedure. The solvent was allowed to evaporate, and the plates were sprayed with p-dimethylaminobenzaldehyde reagent and kept at room temperature for several hours to develop the colour. The obtained azlactones were extracted twice with $1 \mathrm{ml}$ of ethanol, and the absorbance was determined spectrophotometrically against ethanol. Absorption measurements of the orange spots of hippuric acid were carried out at $465 \mathrm{~nm}$ and the greenish-yellow spots of mandelic acid and blue-yellow spots of phenylglyoxylic acid at 220 and $228 \mathrm{~nm}$ respectively.

\section{Results}

As shown in table 1, the $\mathrm{Rf}$ coefficients for hippuric and mandelic acids on plates covered with Silicagel LS 5/40 $\mu$, Kieselgel $\mathrm{HF}_{254}$, MN Kieselgel G, and MN Kieselgel $\mathbf{H}$ in three development systems (B, D, F) are quite different, making the separation procedure simple and giving good reproducibility.

The $\mathrm{Rf}$ coefficients for mandelic and phenylglyoxylic acids on several silicagels are presented in table 1. Relatively good separation was obtained when the analysed compounds were separated on MN Kieselgel $H$ and Silicagel LS $5 / 40 \mu$ in all four developing systems (A, C, G, H). The best separation was obtained when butanol-chloroform-acetic acid and water (G 5:2:1:4) was used. The solvents presented in table 1 are useful when the urinary metabolites of styrene are analysed in the absence of

Table 1 Rf values of hippuric acid $(H A)$, mandelic acid $(M A)$, and phenylglyoxylic acid $(P G A)$ in various solvent systems. (For solvent systems $A-H$, see text)

\begin{tabular}{|c|c|c|c|c|c|c|c|c|c|c|c|c|}
\hline \multirow[t]{2}{*}{ No mixtures } & \multirow[t]{2}{*}{ Metabolites mixtures } & \multicolumn{8}{|c|}{ Adsorbent Silicagel LS $5 / 40 \mu$} & \multicolumn{3}{|c|}{ Kieselgel $H F_{254}$} \\
\hline & & $A$ & $\boldsymbol{B}$ & $C$ & $D$ & $E$ & $F$ & $G$ & $H$ & $\boldsymbol{B}$ & $D$ & $E$ \\
\hline I & $\begin{array}{l}\text { HA } \\
\text { MA }\end{array}$ & & $\begin{array}{l}0 \cdot 13 \\
0 \cdot 27\end{array}$ & & $\begin{array}{l}0 \cdot 27 \\
0 \cdot 49\end{array}$ & & $\begin{array}{l}0 \cdot 19 \\
0 \cdot 32\end{array}$ & & & $\begin{array}{l}0.26 \\
0.41\end{array}$ & $\begin{array}{l}0.40 \\
0.69\end{array}$ & \\
\hline II & $\begin{array}{l}\text { MA } \\
\text { PGA }\end{array}$ & $\begin{array}{l}0.89 \\
0.12\end{array}$ & & $\begin{array}{l}0.91 \\
0.44\end{array}$ & & & & $\begin{array}{l}0.95 \\
0.13\end{array}$ & $\begin{array}{l}0.20 \\
0.53\end{array}$ & & & \\
\hline III & $\begin{array}{l}\text { HA } \\
\text { MA } \\
\text { PGA }\end{array}$ & & & $\begin{array}{l}0.93 \\
0.81 \\
0.55\end{array}$ & & $\begin{array}{l}0.78 \\
0.66 \\
0.37\end{array}$ & & & $\begin{array}{l}0.07 \\
0.16 \\
0.46\end{array}$ & & & $\begin{array}{l}0.64 \\
0.60 \\
0.20\end{array}$ \\
\hline
\end{tabular}


Table 2 Colour reactions of hippuric acid $(H A)$, mandelic acid $(M A)$, and phenylglyoxylic acid $(P G A)$ with various developing reagents. (For reagent a-d and solvent system $H$, see text)

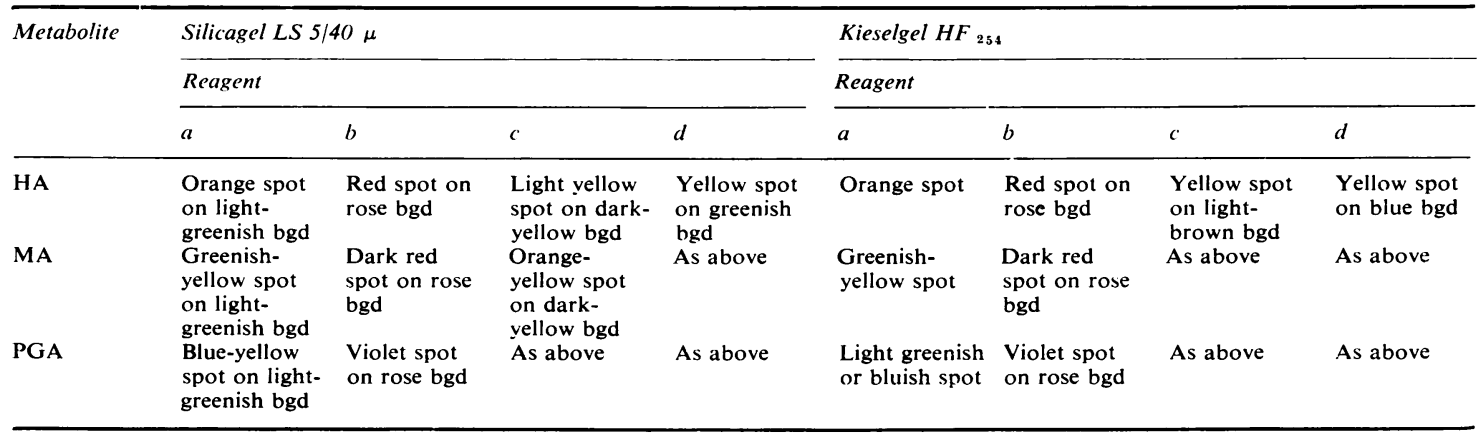

bgd = Background.

toluene-exposure.

The separation of all three compounds produces the greatest difficulties. In table 1 the $\mathrm{Rf}$ values for hippuric acid, mandelic acid, and phenylglyoxylic acid on various silicagels and kieselgels are presented when three developing solvents $(\mathrm{C}, \mathrm{E}, \mathrm{H})$ are used. The best results were obtained when the solvent system $\mathbf{H}$ (light petroleum-benzene-chloroform-acetic acid-water $(3: 3: 4: 2: 2)$ was used. The optimalisation of colour production when spots of hippuric acid, mandelic acid, and phenylglyoxylic acid are present on the plates are shown in table 2 . The best results were obtained when p-dimethylaminobenzaldehyde in acetic acid anhydride was used. Hippuric acid under the described conditions forms an orangecoloured spot, which, after elution with ethanol, gives an absorption maximum at $465 \mathrm{~nm}$ when measured versus ethanol. Mandelic acid forms a greenishyellow spot that after elution with ethanol, shows two maxima at $220 \mathrm{~nm}$ and at about $345 \mathrm{~nm}$.

Phenylglyoxylic acid gives a light yellow-blue spot showing absorption in the range between 250 and $350 \mathrm{~nm}$ with a maximum of $228 \mathrm{~nm}$. The intensity of the coloured substance produced by mandelic and phenylglyoxylic acids increases, reaching a constant value after a few hours.

As shown in table 2, the analysed metabolites are detectable as coloured spots on the chromatographic plates after appropriate development.The separations were carried out on Silicagel LS 5/40 $\mu$ and Kieselgel $\mathrm{HF}_{254}$ in the developing system-(light petroleumbenzene-chloroform-acetic acid-water $(3: 3: 4: 2: 2))$. The best of the developing reagents was p-dimethylaminobenzaldehyde, which produces coloured compounds with both mandelic and phenylglyoxylic acids after a few hours. Bromophenol-blue which gives yellow spots on a blue or green background is also useful because of the almost immediate colour production.

The absorption maxima of the coloured compounds was, for mandelic acid, $218 \mathrm{~nm}$, for hippuric acid, $227 \mathrm{~nm}$, and for phenylglyoxylic acid, $234 \mathrm{~nm}$.

\section{Discussion}

We have shown that, after mixed exposure to styrene and toluene, the urinary metabolites of these substances may be separated and quantitatively determined. Satisfactory results were obtained when the analysed metabolites were developed in light petroleum-benzene-chloroform-acetic acid-water $(3: 3: 4: 2$ : 2) on Kieselgel $\mathrm{HF}_{254}$, MN Kieselgel $\mathrm{H}$, and Silicagel $5 / 40 \mu$.

When workers were exposed only to styrene, both

\begin{tabular}{|c|c|c|c|c|c|c|c|c|c|c|c|c|c|}
\hline$F$ & $G$ & $H$ & \multicolumn{7}{|c|}{ MN Kieselgel $H$} & \multicolumn{4}{|c|}{$M N$ Kieselgel G } \\
\hline $\begin{array}{l}0.31 \\
0.43\end{array}$ & & & & $\begin{array}{l}0.38 \\
0.54\end{array}$ & & $\begin{array}{l}0.50 \\
0.68\end{array}$ & $\begin{array}{c}0.37 \\
0.50\end{array}$ & & & $\begin{array}{l}0.45 \\
0.65\end{array}$ & $\begin{array}{l}0.50 \\
0.77\end{array}$ & $\begin{array}{l}0.25 \\
0.37\end{array}$ & \\
\hline & 0.94 & 0.29 & 0.78 & & 0.66 & & & 0.87 & 0.24 & & & & 0.84 \\
\hline & 0.07 & 0.55 & 0.49 & & 0.52 & & & $0 \cdot 12$ & 0.78 & & & & 0.09 \\
\hline & & $0 \cdot 11$ & & & 0.72 & & & & 0.07 & & & & \\
\hline & & 0.23 & & & 0.63 & & & & $0 \cdot 23$ & & & & \\
\hline
\end{tabular}


metabolites (mandelic acid and phenylglyoxylic acid) were satisfactorily separated in n-butyl alcoholchloroform-acetic acid-water $(5: 2: 1: 4)$ on Kieselgel $H^{254}$, MN Kieselgel $\mathrm{G}, \mathrm{MN}$ Kieselgel $\mathrm{H}$, and Silicagel LS $5 / 40 \mu$. The developing reagent proposed by Ogata et al ${ }^{15}$ for hippuric acid determination based on p-dimethylaminobenzaldehyde also enables mandelic acid and phenylglyoxylic acid to develop. The coloured substances produced when mandelic acid and phenylglyoxylic acid were present in the analysed urine sample are probably produced during longer direct contact of these substances with the developing reagent because, as mentioned above, the intensity of the colour increases after prolonged time of development. The present method gives quite good separation of the analysed compounds as well as relatively good and reproducible quantitative results.

This procedure may be used when exposure to both toluene and styrene, or styrene alone, has to be evaluated. The simplified procedure involving TLC techniques may be used in some factory laboratories. The lowest quantities of the analysed substances were $6 \mu \mathrm{g}$ for hippuric acid, $10 \mu \mathrm{g}$ for mandelic acid, and $7 \mu \mathrm{g}$ for phenylglyoxylic acid. When the concentration of these substances in urine is lower than the above mentioned values, the urine samples have to be concentrated by evaporation under low pressure. The exactness of determination was $\pm 4 \cdot 7, \pm 9 \cdot 4$, and $\pm 8.4 \%$ for hippuric, mandelic, and phenylglyoxylic acids respectively. The presented accuracy is good enough to evaluate occupational exposure to toluene and styrene.

\section{References}

${ }^{1}$ Vivoli G, Vecchi G. Ricerche sulla escrezione urinaria di acido mandelico quale test di esposizione allo stirolo. Lav Um 1974;26:1-9.

${ }^{2}$ Engstrom K, Harkonen $\mathrm{H}$, Kalliokoski P, Rautanen J. Urinary mandelic acid concentration after occupational exposure to styrene and its use as a biological exposure test. Scand J Work Environ Health 1976;2:21-6.

${ }^{3}$ Fields RL, Horstman SW. Biomonitoring of industrial styrene exposures. Am Ind Hyg Assoc J 1979;40:451-9.

4 Ohtsuji H, Ikeda M. A rapid colorimetric method for the determination of phenylglyoxylic and mandelic acids. Br J Ind Med 1970;27:150-4.

${ }^{5}$ Horigushi $\mathrm{S}$, Teramoto $\mathrm{K}$. Industrial styrene poisoning. III Upper limits of MA and PGA normally excreted in the urine as an index of styrene exposure. Sangvo Igaku 1972;14:288-9.

${ }^{6}$ Ikeda M, Imamura T, Hayashi M, Tabuchi T, Hara I. Evaluation of hippuric, phenylglyoxylic and mandelic acids in urine as indices of styrene exposure. Internationales Archiv fur Arbeitsmedizin 1974;32:93-101.

${ }^{7}$ Horigushi S, Teramoto K, Kiyota I, Endo G. Industrial styrene poisoning. V Daily variations in the amount of mandelic, phenylglyoxylic and hippuric acids excreted in the urine of styrene workers. Sangyo Igaku 1974;16: 228-9.

${ }^{8}$ Ikeda M, Ohtsuji H. Significance of urinary hippuric acid determination as an index of toluene exposure. $\mathrm{Br} J$ Ind Med 1969;26:244-6.

${ }^{9}$ Wilczok T, Bieniek G. Urinary hippuric acid concentration after occupational exposure to toluene and its use as biological exposure test. $\mathrm{Br} J$ Ind Med 1978;35:330-4.

${ }^{10}$ Wood SG, Al-Ani MR, Lawson A. Hippuric acid excretion after benzylamine ingestion in man. $\mathrm{Br} J$ Ind $\mathrm{Med}$ $1978 ; 35: 230-1$.

${ }^{11}$ Buchet JP, Lauwerys RR, Roels H. Evaluation de l'exposition des travailleurs an styrene par le dosage de'ses métabolites urinares: les acides mandélique et phénylglyxolique. I Technique de dosage des métabolites par chromatographic en phase gazense. Archives des Maladies Professionelles de Medicin du Travail et de Securité Sociale 1974;35:507-12.

${ }^{12}$ Bauer D, Guillemin M. Human exposure to styrene. I. The gaschromatographic determination of urinary phenylglyoxylic acid using diazomethane derivatization. Int Arch Occup Environ Health 1976;37:47-55.

13 Guillemin M, Bauer D. Human exposure to styrene. II Quantitative and specific gaschromatographic analysis of urinary mandelic and phenylglyoxylic acids as an index of styrene exposure. Int Arch Occup Environ Health 1976; 37:57-64.

${ }^{14}$ Ikeda M, Ohtsuji H. Hippuric acid, phenol, and trichloroacetic acid levels in the urine of Japanese subjects with no known exposure to organic solvents. Br J Ind Med 1969; 26:162-4.

15 Ogata M, Tomokuni K, Takatsuka Y. Quantitative determination in urine of hippuric acid and $\mathrm{m}$ - or p-methylhippuric acid, metabolites? of toluene and $\mathrm{m}$ - or p-xylene. Br J Ind Med 1969;26:330-4. 